\title{
Magnetic fabric analysis in a mesoscopic fold
}

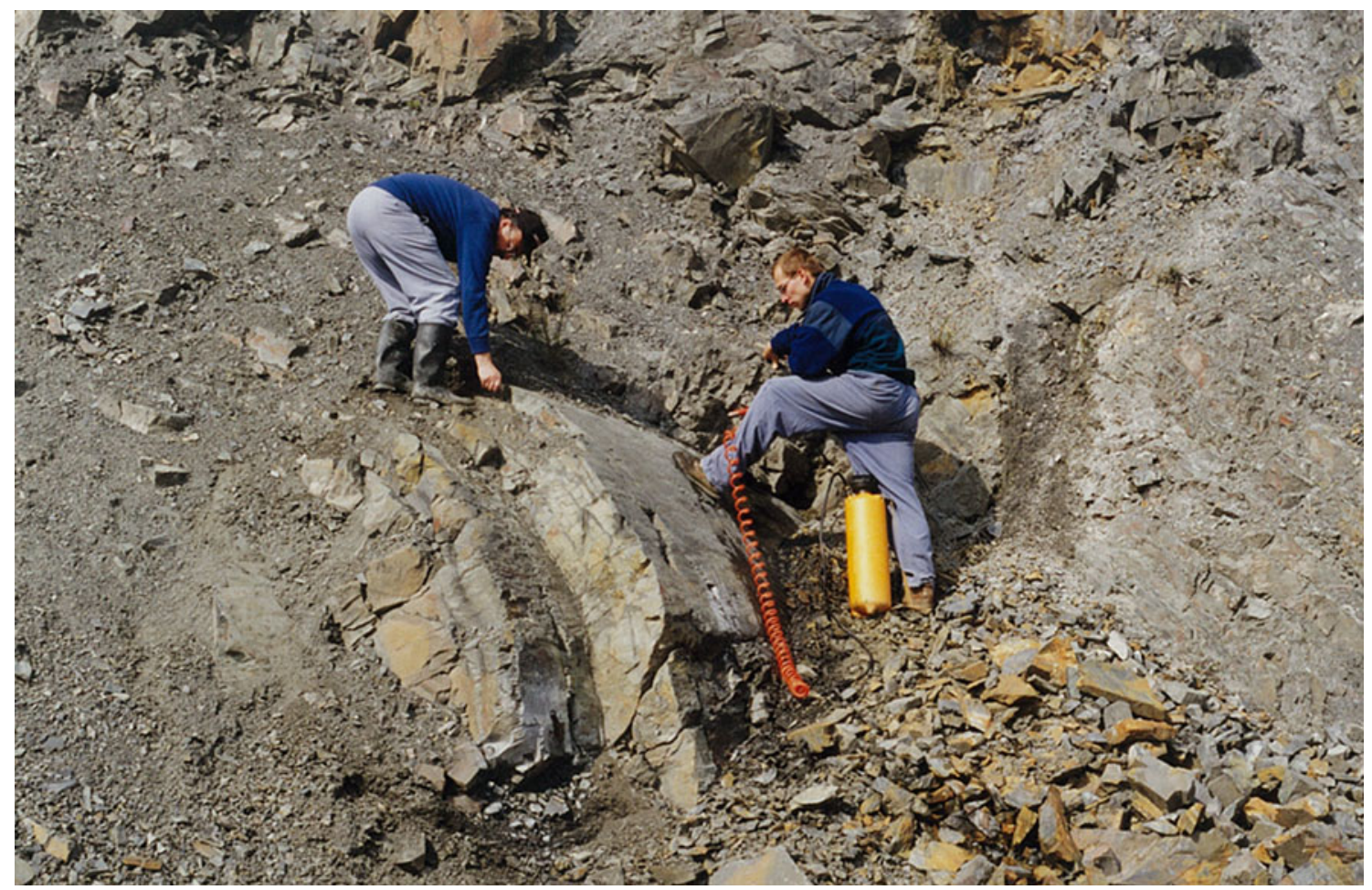

A mesoscopic fold in the Lower Carboniferous flysch formation of the Rheno-Hercynian Belt (Hrabůvka quarry, NE part of the Czech Republic). František Hrouda (wearing a cap) is standing on the hinge of the fold, while Martin Chadima (then František's field assistant) drills cores for magnetic fabric analysis. Acquired data were later published in Hrouda et al. (2000). The photograph was taken by Oldřich Krejčí in 1998.

\section{Reference}

Hrouda F, Krejčí O, Otava J (2000) Magnetic fabric in folds of the easternmost Rheno-Hercynian Zone. Phys Chem Earth Part A Solid Earth Geodesy 25:505-510

M. A. Mamtani ( $\square)$

Indian Institute of Technology Kharagpur, Kharagpur, India

e-mail: mamtani@gg.iitkgp.ernet.in

\section{Chadima}

AGICO Inc., Brno, Czech Republic

H. de Wall

Universität Erlangen-Nürnberg, Nuremberg, Germany

R. O. Greiling

Karlsruher Institut für Technologie, Karlsruhe, Germany

Published online: 7 February 2012

(C) Springer-Verlag 2012 